\title{
Analysis on the Increase in Negative Emotions of Online Learning During the Pandemic
}

\author{
Tianyang $\mathrm{Hu}^{1, *}$ \\ ${ }^{1}$ University of California Irvine, Irvine, CA, 92612, the United States \\ *Corresponding author.Email: tianyah5@uci.edi
}

\begin{abstract}
Starting from the very beginning of 2020, the spread of Covid-19 asked people to stay at home and cut down almost all their contacts with the outer world. Even for the necessary social activities, wearing a mask and keeping a distance is required, which had completely changed the living for almost all people in the world. Families can't go and have a picnic, friends can't have parties, and students and workers can't go to their workplace. But new lifestyles occur subsequently, one of which is the switch to online learning and working. The novel and unfamiliar environment create lots of new opportunities as well as challenges for students and workers. This study, by unfolding the personal experiences of people around me and data collected by authorities, is going to analyze the underlying problems and proposing possible corresponding solutions to this new study method during this special time period. As the analysis shows in this paper, the decrease in social integration is the main cause of depressive emotions.
\end{abstract}

Keywords: Online/remote learning, Difficulties of online learning, Education inequalities of online learning, Methods to improve online learning.

\section{INTRODUCTION}

The means of conducting effective and reasonable use of technology have proved to be a decisive factor for modern people to succeed, for misuse of technology will not only distract people from concentrating on their works but also creates immersive negative emotions. This idea has been especially emphasized during 2020, while a worldwide virus has spread out and forced people to stay at home and finish their works mainly online. When problems occur, however, people tend to ascribe the causes to an individual's inaction, but they tend to ignore the impact of the society - the surrounding circumstances as a system. In a survey conducted by Beijing Normal University, $70 \%$ of the teachers responded that they were meeting difficulties while teaching online, proving the problems of online learning to be a prevailing social problem instead of individual imprecations[1]. This paper targets at revealing society's obligations of creating problems for online learning in response to two major problems of online learning: increase anxiety and other negative emotions, and greater inequalities, discussing possible solutions and underlying difficulties of them. It is hoped that this research can awaken and gather society's attention to regard the problems of online learning as a social problem instead of a personal obstacle, and afterwards, publishing pointed policies to ease individual's pressures.

\section{INCREASE IN THE ANXIETY AND OTHER NEGATIVE EMOTIONS}

On May 13, 2020, WHO reported that "3-fold increase in the prevalence of symptoms of depression compared to estimates from before the epidemic".[1] And social phenomenons also gave supports to that. In early July, the name of "Net Depressed Cloud Music" (original name: Netease Music) had been popularized quickly online. One of the reasons was that Depressed and Easy has a similar pronunciation in Chinese, and another important reason is that there are a lot of people commenting on their negative emotions on it.

Specifically, during online learning, students expressed themselves as increasingly stressed out because of the time difference, schoolwork that fails to reach out for help, or intangible deadlines. 
Increased students were reported to have psychological problems, and the number of suffering students continues to accumulate.

The causes of these problems are worth analyzing.

\subsection{Decrease in Social Integration}

The first one is because of the sudden drop in social integration. Emile Durkheim wrote in his book "Suicide" that "what constitutes this society is the existence of a certain number of beliefs and practices common to all faithful, traditional and thus obligatory the essential thing is that they are capable of supporting a sufficiently intense collective life."[2] He argues that strong social connections would have a moderating effect upon his or her negative emotions and actions. That argument could perfectly fit into the existence of schools and co-working places. While a student or a worker is working in circumstances in which other people are performing similar tasks with them, they will get greater responsibilities for fulfilling their works. Because they together - all individuals in that system - construct an atmosphere of norms, requiring each one to concentrate on the progress of their works. This subtly helps to reject individual quits, because of the unwillingness of rulesbreaking. Further, working as a system, when anyone in that system meets problems, others can instantly stand out to help.

Moreover, it is built upon a persuasive collective value, which helps to defend the frustration and helplessness.

However, the distance between each participant of online learning stops that spirit to form in virtual classes. Students can now neither find peers who work equally diligently on schoolwork or seek others' support and helps when problems come. Worse, the epidemic widens gaps between students of different racial or status (discussed later). The last president of American, Trump Donald, once peaked in public to name the virus "Chinese virus". From them, statements tended to be pointed directly to China. And soon, a society formed racial segregation between yellow skin people and the rest people. Even though the "Chinese virus" was proved to be incorrect later, there are still numerous people who would consider the virus was originally created by China and then spread out to the rest of the world. Because when uncertainty comes to society, excluding a certain group of people will reunify the rest and give back them the sense of stableness [3]. The quick emerge of an unknown new virus arose fears in almost all people's minds, and thus they needed to justify to themselves that there was clearly a group of people who should be responsible for the problem. As a result, they targeted the country where the virus was first detected and its residents. However, that isolation and distance between different students intensified the decrease of social integration among students, leaving them with a strong sense of despair and depressions.

\subsection{Misuse of the Internet}

Another cause is the Internet. Nowadays the quick pace of updates of information impacts the news editors to capture the readers' interests for a long time. As a result, they tend to utilize the readers' fear to catch their attention. They sneeze the public fear and exaggerate it in their reports. Moreover, once the public sees that, they tend to believe what the media says. That is "availability heuristic", and that is "if it comes to mind easily, it must be true". So during the epidemic, lots of media were reporting the seriousness of the virus - how many deaths it had led to, how great sequela the recovery will leave, and how long people can't back to normal life. All this information terrifies the public. The media convinces people that there will be a long-lasting impact on its normal life, which could hardly be edited or adjusted. Students, the group in a society that will mostly be persuaded, believe that the steadiest. As a result, they immerse themselves in the uncertainty of their future of study or career and fail to release themselves from negative emotions.

\section{GREATER INEQUALITY}

Closures of schools and other learning spaces have impacted 94 percent of the world's student population, up to 99 percent in low and lowermiddle-income countries. [4] Although some people argue that online learning creates easier access for students who used to be restricted by graphical factors, they are now facing other more serious problems. It is true that virtual classes have fewer requirements for local schools - classrooms, advanced teaching devices, and experienced teacher, but students can hardly be guaranteed to have stable access to the Internet, communication devices, or even electricity. As the survey done by USA Facts reports, 4.4 million households with students still lack consistent access to a computer and 3.7 million lack internet access.[5] As a result, 
once teachers are blocked at home and fail to go to the schools to give lectures, students now are forced to quit studying. The giving-up action will be especially common among girls who were initially discouraged to go to school. Parents now can take the obstacles of registering into online courses as "legitimate" reasons to stop their daughters to be educated. On the other hand, for boys, to whom education is often viewed as important and necessary, parents will try harder to offer them opportunities to have online courses. Consequently, greater inequalities will be left among education resources received by boys and girls. In high school, a club is set to teach primary school's leftover students in countryside communities. This work is completely voluntary - no tuition fees or other requirements. At the beginning of the epidemic, in consideration of the increase in the confusion they might meet because of online learning, the club decided to continue our work remotely through WeChat. However, at the very beginning of the first semester, three girls (a total of 7) said that they will no longer participate in the course because of inaccessibility to the internet or the family's requirement for them to look after their younger sisters or brothers.

Further, online learning posts other requirements for a student to succeed, and one of which is the family background. For remote teaching, teachers tend to focus on correcting the mistakes students made in homework and quiz instead of the completion and degree of understanding of the knowledge. This is evidenced by a multi-year mixed-method study on digital learning in a large area of the Midwest. [6] Students seek alternative sources to gain help on their study materials. For students whose parents are both welleducated with high educational background, they can easily turn to their parents to get reliable and straightforward answers. In addition, since the virus sticks children at home with their parents, these students' parents can share relevant knowledge and even necessary career information, which would be helpful to students' further learning. By contrast, students whose parents haven't received enough education training would fail to give academic supports to their children, who would in turn spend more time and meet more difficulties as results to terminate at the correct answers. Accumulatively, when coming back to schools, students will be invisibly divided into groups that get sufficient education training and groups that lack effective and thorough understandings of concepts. This will leave a remarkable impact on the future success of this generation of students.

\section{CONSEQUENCES AND POSSIBLE SOLUTIONS}

The direct result of countless negative emotions and inequalities will be an increase in the drop-off rate for students. Because the negative emotions would stimulate students' self-doubts, which would in turn affect their academic performances negatively. ". Academic self-confidence can be viewed as a separate and more specific term, which can be referred to in educational settings as a predictor of academic performance." Said Vrugt et al. (1997). Combining with the sense of helplessness to succeed and the difficulties of accessing education resources, it is predictable that the drop-off rates for students will increase in 2020. And studies show that there is a correlation between the drop-off rate and the commitment rate of criminals (see "Figure 1" and "Figure 2" below, the left one is the relationship between the age and commitment rate of crimes and the right is the relationship between the age and commitment rate of crimes), [7] and this is because the education intensifies teenagers' sense of norms and morals, discouraging them from violating other's interests.

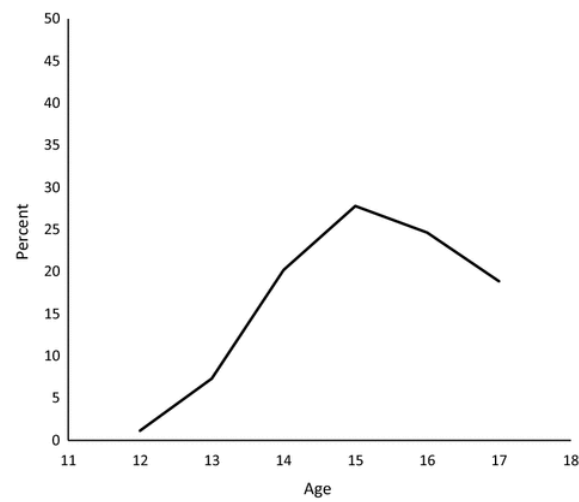

Figure 1 Relation between age and drop-off rate.

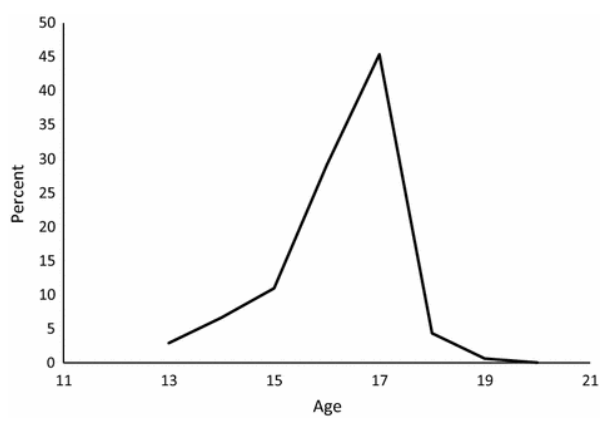

Figure 2 Relation between age and commitment rate of criminals. 
As problems and possible consequences clear out, solutions need to be posted. Lots of individuals are taking action to solve the problems listed online. Some universities are now affording their students with necessary technical devices to support them to conduct the online learning process. For example, some private companies have begun to provide free education services to students and schools.

But as a system, society needs to take action as well. Since the companies need profit to operate normally and schools' funds will be limited, society needs to help to solve the problems. And apparently, simply offering funds would be impossible in the long run since, just as the schools and companies, the budget of the government need to take into consideration.

One of the possible solutions would be circulating education resources. In the cities' schools, which students and teachers now have little needs, there will be resources helpful for peers in the countryside. By collecting resources and spreading them out to the places that the internet or computers are not covered, the government can solve the inequalities in these places.

Another solution will be adding free advertisements for crimes prohibitions. As there will still be students dropping off from schools even if the inequalities have been partially solved, it is important to propagandize the harm of crime to teenagers, their families, and the societies. Further, greater security is needed to guard against possible threats to society's safety.

\section{CONCLUSION}

To conclude, the remote teaching style will amplify student's self-doubt and creates greater inequalities both because of lack of technical supports and lack of family supports. Students now will face greater difficulties to succeed in their academic fields. As a result, more students will result in quit their studies or switch to take a job alternatively. An increase in the rate of decline will lead to greater investment in crime. This could not be solved purely by individuals, since the major cause is the lack of social integrations and social support. Actions need to be taken by society as a whole.

\section{AUTHORS' CONTRIBUTIONS}

This paper is independently completed by Tianyang $\mathrm{Hu}$.

\section{ACKNOWLEDGMENTS}

I appreciate the guidance from my professors and teaching assistants, further, I would like to thank all my friends and my parents for their support.

\section{REFERENCES}

[1] World Health organization. "Rolling update on coronavirus disease(COVID-19)" UN Policy Brief on COVID-19 and the Need for Action on Mental Health, 13 May 2020, www.who.int/emergencies/diseases/novelcoronavirus-2019/events-as-they-happen.

[2] Emile, Durkheim. Suicide. 1897.

[3] Emile, Durkheim. The Division of Labor in Society. 1960.

[4] United Nations, "Education during COVID-19 and beyond", August 2020, https://www.un.org/development/desa/dspd/w $\mathrm{p}-$ content/uploads/sites/22/2020/08/sg_policy_br ief_covid-19_and_education_august_2020.pdf

[5] USAFacts, "4.4 million households with children don't have consistent access to computers for online learning during the pandemic", September 28, 2020, https://usafacts.org/articles/internet-accessstudents-at-home/

[6] Darling Aduana, Jeniffer, et al. "Online Leaning and Implications for Inequality in the Classroom." Scholars, 11 July 2019, scholars.org/contribution/online-learning-andimplications-inequality-classroom.

[7] Iryna Rud, Chris van Klaveren, Wim Groot, Henriëtte Maassen van den Brink. "What Drives the Relationship Between Early Criminal Involvement and School Dropout". October, 12, 2016. 